\begin{tabular}{|c|c|c|}
\hline $\begin{array}{l}\text { PKS } \\
\text { PUBLIC } \\
\text { KNOWLEDGE } \\
\text { PROJECT }\end{array}$ & $\begin{array}{c}\text { REVISTA DE GEOGRAFIA } \\
\text { (RECIFE) } \\
\text { http://www.revista.ufpe.brrevistageogratia }\end{array}$ & $\begin{array}{l}\text { OJS } \\
\begin{array}{l}\text { OPEN } \\
\text { JOUNAL } \\
\text { SYSTEMS }\end{array}\end{array}$ \\
\hline
\end{tabular}

\title{
ANÁLISE DAS QUEIMADAS NO CERRADO E SUA RELAÇÃO COM O NDVI PARA OS ANOS DE 2000 A 2014
}

\author{
Paula Resende Santos ${ }^{1}$; Gabriel Pereira ${ }^{2}$; Francielle da Silva Cardozo ${ }^{3}$; Raquel de \\ Cássia Ramos ${ }^{4}$; André Barbosa Ribeiro Ferreira ${ }^{5}$; Fernanda Cristina Resende ${ }^{6}$
}

${ }^{1}$ Universidade Federal de São João del-Rei.Email: paularesendesantos@gmail.com

${ }^{2}$ Universidade Federal de São João del-Rei.Email: pereira@ufsj.edu.br

${ }^{3}$ Universidade Federal de São João del-Rei.Email: franciellecardozo@ufsj.edu.br

${ }^{4}$ Universidade Federal de São João del-Rei.Email: raquel.cassia15@gmail.com

${ }^{5}$ Universidade Federal de São João del-Rei.Email: andreribeirogeo@gmail.com

${ }^{6}$ Universidade Federal de São João del-Rei.Email: fecrisresende@yahoo.com.br

Artigo recebido em 17/11/2016 e aceito em 06/11/2017

\section{RESUMO}

Este trabalho tem como objetivo quantificar e espacializar queimadas obtidas a partir dos produtos MYD14 e MOD14 estimadas pelo sensor MODIS que ocorrem em todo o Cerrado. Os dados de queimadas foram comparados com os dados do produto do índice de vegetação denominado MOD13A3 NDVI (para pontos sorteados), também estimados pelo sensor MODIS a fim de compreender as interferências das queimadas na resposta biofísica da vegetação e suas mudanças em uma série temporal de 14 anos (2000 - 2014) a partir da Transformada Wavelet. A análise da distribuição espacial dos focos de queimadas indica que os locais mais atingidos pelas queimadas ocorrem em áreas de savana na porção norte do bioma. A utilização da Tranformada Wavelet para analisar variações nos sinais de NDVI se mostrou eficiente para verificar os cenários passados e atuais da vegetação, além de auxiliar na análise do comportamento fenológico da vegetação.

Palavras-Chave: Cerrado, MODIS, queimada, NDVI

\section{BURNED AREAS ANALYSIS IN CERRADO BIOME AND THE RELATIONSHIP WITH NDVI FROM 2000 TO 2014}

\begin{abstract}
The objective of this study is quantify and spatialize the fires occurred in Cerrado biome from MYD14 and MOD14 products estimated by MODIS. The fire occurrence were compared with the data of vegetation index product called MOD13A3 NDVI (to the selected points), also estimated by MODIS sensor to understand the interference of fires in biophysical response of the vegetation and the changes in a temporal series of 14 years (2000-2014) using Wavelet Transform. The spatial analysis of fire occurrence indicates that the most affected areas are located in savanna areas of northern portion of the biome. The using of Wavelet Transform to analyze variations in NDVI signal was efficient to verify the past and current scenarios of vegetation, as well as, to support the phenological behavior of vegetation.
\end{abstract}

Key Word: Cerrado, MODIS, fire, NDVI 


\section{INTRODUÇÃO}

Com a descoberta do fogo, a pelo menos 10.000 anos, o homem passou a utilizá-lo amplamente como instrumento de manejo agrícola, seja para a renovação de pastagem ou como mecanismo de conversão do uso e cobertura da terra (BELCHER, 2013). Atualmente, os ecossistemas tropicais são os mais atingidos pelas queimadas em todo o globo, no qual o tipo de combustível (a biomassa florestal), o clima e a fonte de ignição são componentes necessários para um incêndio (NEPSTAND et al., 1999). Estima-se que até $90 \%$ das queimadas são de origem antropogênica, tornando pouco significativo as ignições de origem natural por raios (ANDREAE, 1991).

No Brasil, os maiores registros ocorrem no período seco, principalmente no Cerrado, pois o ecossistema fornece um combustível fino e seco de fácil ignição próximo ao solo, tornando as queimadas um vetor de transformação do uso e cobertura da terra. O Cerrado é considerado a última fronteira agrícola, e as mudanças de uso e cobertura ocorrem em grande velocidade, onde aproximadamente $55 \%$ da sua vegetação natural já foram convertidas para usos agrícolas e pastagens. As alterações da paisagem natural do Cerrado ocorrem em função das inovações tecnológicas, investimentos de capital e conhecimento científico para promover a expansão da agricultura extensiva e sustentar o mercado de commodites agrícolas, colocando o Cerrado como hotspot mundial de biodiversidade (KLINK; MACHADO, 2005).

Embora algumas espécies deste bioma sejam adaptadas ao fogo, estudos sugerem que a recorrência de queimadas podem mudar a fisionomia do Cerrado para campos abertos, tornando as gramíneas como o principal componente estrato herbáceo, o que resulta em um maior acumulo de biomassa, que tem como consequência maior frequência e incêndios com altas temperaturas, que pode prejudicar a fauna e flora, além de expor o solo aos processos erosivos e de lixiviação (MIRANDA et. al, 2002). A queima de biomassa também está associada com a emissão de gases traços e aerossóis, que perturbam o ciclo de carbono, além de alterar a composição química da atmosfera em escala local, regional e global e podem atingir o balanço hídrico, diminuindo os registros de precipitação (COCHRANE, 2009; BELCHER, 2013).

$\mathrm{O}$ advento do Sensoriamento Remoto permitiu uma melhor observação da terra em uma escala global e periódica facilitando a análise de fenômenos dinâmicos como as mudanças na cobertura vegetal e a fenologia em uma série temporal, contribuindo para a observação dos impactos das queimadas sobre a vegetação e seu uso como instrumento de manejo. Neste contexto, o sensor Moderate Resolution Imaging Spectroradiometer (MODIS) 
a bordo das plataformas Aqua e Terra iniciou um novo paradigma na detecção de focos de queimadas, oferecendo aos usuários uma alta resolução temporal e também melhorias na resolução espectral e radiométrica quando comparado ao GOES (Geostationary Operational Environmental Satellite) e aos sistemas do NOAA/AVHRR (National Oceanic Atmospheric Administration) (ANDERSON, L. O. et al, 2005)

Deste modo, este trabalho tem como objetivo quantificar e espacializar as queimadas no Cerrado de 2000 a 2014, além de analisar sua interferência na resposta biofísica da vegetação e as mudanças de uso e cobertura da terra para esta série temporal.

\section{ÁREA DE ESTUDO}

Localizado na porção central do Brasil, o cerrado é o segundo maior bioma brasileiro, ocupando aproximadamente $23,92 \%$ da área total do território nacional (IBGE, 2004), demonstrado na figura 1. O bioma, que está localizado na zona equatorial, limita-se com a floresta amazônica ao norte, com os domínios da mata atlântica ao sul e ao sudeste e com a caatinga na região semiárida nordestina, sendo que estas regiões entre os biomas denominam-se ecótonos e são consequências da interpenetração de dois ou mais domínios morfoclimáticos denominadas "faixas de transição” (AB’SÁBER, 1971).

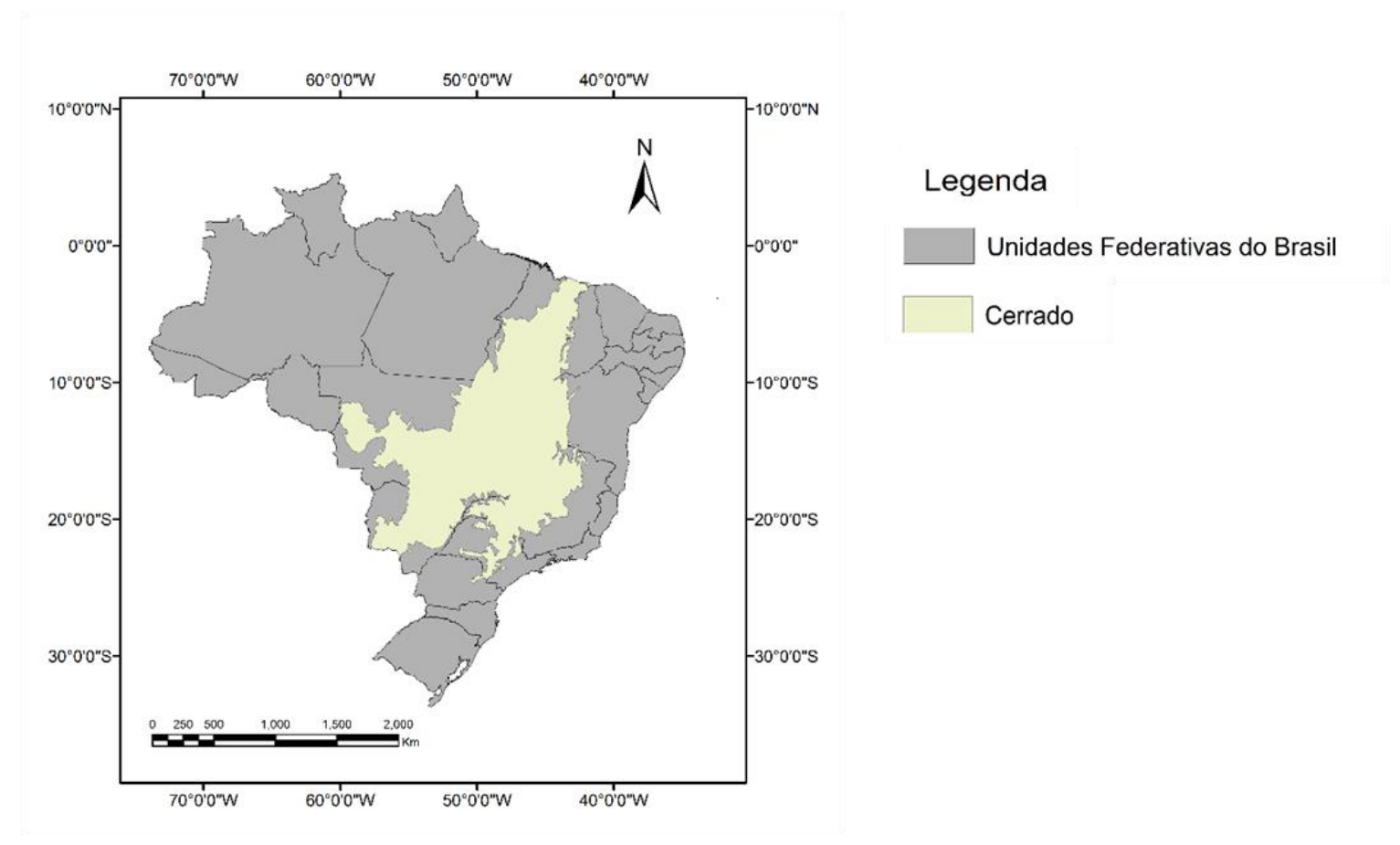

Figura 1: Localização do Bioma Cerrado 
O bioma abrange o Distrito Federal e os estados de Goiás, Tocantins e parte dos estados da Bahia, Ceará, Maranhão, Minas Gerais, Mato Grosso, Mato Grosso do Sul, Piauí, Rondônia e São Paulo, e ocorre de forma disjunta na Floresta Amazônica, denominada “Savana Amazônica” (RIBEIRO; WALTER, 2008). As precipitações anuais médias no Cerrado estão entre 1.200 e $1.600 \mathrm{~mm}$, com registros pluviométricos que variam entre $2.000 \mathrm{a}$ 2.200 mm no limite com a floresta Amazônica e entre 600 e 800 na interface com a Caatinga. O clima para a região é definido como Tropical Sazonal, com duas estações bem definidas, uma seca que se inicia em Maio e se estende até Setembro e outra chuvosa que vai de Outubro a Abril. Durante o período de seca ocorrem os maiores registros de incêndios, onde as baixas umidades do ar relacionadas ao grande volume de biomassa seca contribuem para propagação e manutenção do fogo (MMA, 2011).

A localização geográfica do Cerrado no Planalto Central faz com que o bioma tenha um papel fundamental na distribuição dos recursos hídricos no país, sendo local de origem de grandes bacias brasileiras. Os principais rios que recebem contribuições das áreas do Cerrado são os da Bacia Amazônica (Rios Xingu, Madeira e Trombetas); Bacia do Tocantins (Rios Araguaia e Tocantins); Bacia do Atlântico Norte/Nordeste (Rios Parnaíba e Itapecuru); Bacia do São Francisco; Bacia do Atlântico Leste (Rio Pardo e Jequitinhonha) e a Bacia do Paraná/Paraguai (LIMA e SILVA, 2008).

Os principais tipos de vegetação para o Bioma Cerrado se diferenciam principalmente pela fisionomia (forma), fatores edáficos e composição florística. Os onze principais tipos fitofisionômicos para o bioma estão divididos em: formações Florestais (Mata Ciliar, Mata de Galeria, Mata Seca e Cerradão), Savânicas (Cerrado stricto sensu, Parque de Cerrado, Palmeiral e Vereda) e as formações Campestres (Campo sujo, Campo Limpo e Campo Rupestre), demonstrados esquematicamente na Figura 2. 


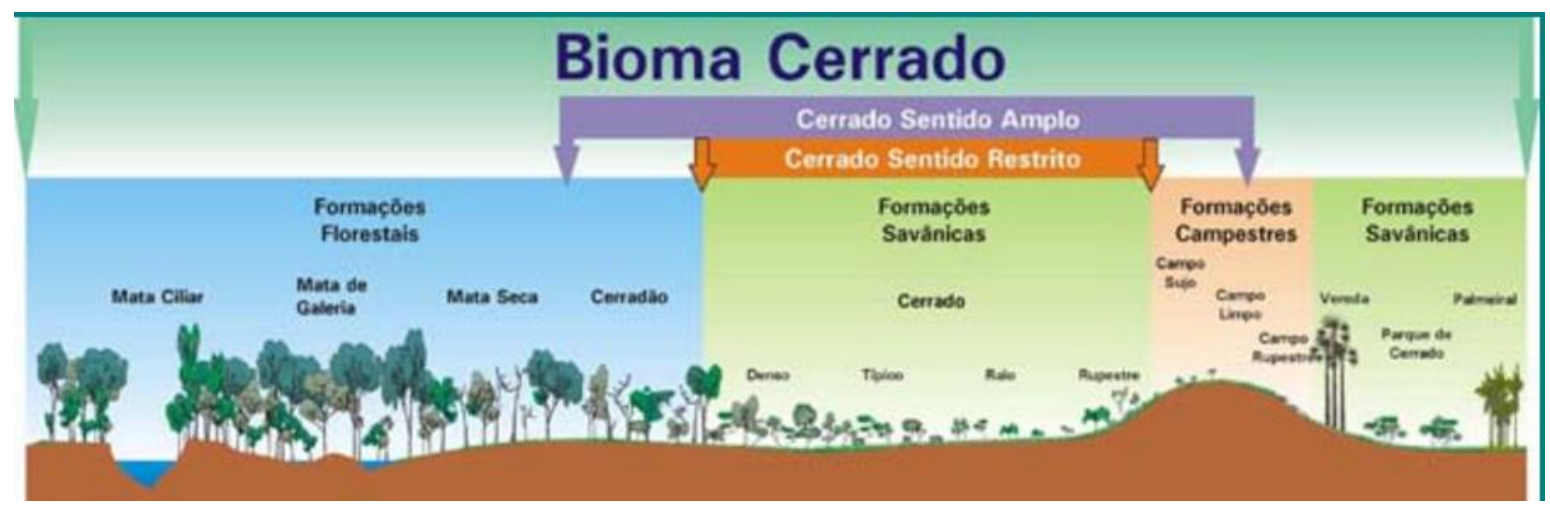

Figura 2: Esquema das onze principais fitofisionomias do Bioma Cerrado separadas de acordo com a formação florestal.

Fonte: Ribeiro e Walter, 2008

$\mathrm{Na}$ década de 60 a agricultura passou a integrar o desenvolvimento econômico brasileiro, através de políticas públicas voltadas para a modernização deste seguimento aliadas a necessidade de expansão da fronteira agrícola. Neste contexto, o Cerrado que até então não possuía potencial agrícola (exceto nos solos aluviais nas margens dos canais) devido à baixa fertilidade do solo, passou a ser explorado com o incremento de adubos e sementes geneticamente modificadas (BORLAUG, 2002; AGUIAR e MONTEIRO, 2005). Atualmente, o bioma tem como maior desafio a conciliação dos seus recursos naturais com o desenvolvimento econômico, pois suas características propícias à agricultura e à pecuária fazem com que haja uma maior conversão da sua cobertura vegetal para estes fins (NETO e MORAIS, 2003).

\section{MATERIAIS E MÉTODOS}

MOD13A3

Um dos Índices de Vegetação (IV) amplamente utilizados para a modelagem de parâmetros biofísicos é o Normalized Difference Vegetation Index (NDVI) ou Índice de Vegetação por Diferença Normalizada (IVDN) proposto por Rouse et al. (1973), que corresponde à razão entre a diferença e a soma das reflectâncias das bandas no infravermelho próximo (IVP) e no vermelho (V), descrito na fórmula 1. O Infravermelho próximo está situado entre 0,7 e 1,3 $\mu \mathrm{m}$ no espectro eletromagnético (EEM) e a reflectância nesta região em uma planta sadia é elevada em virtude dos múltiplos espalhamentos que ocorrem devido às descontinuidades entre os índices de refração do ar e da água presentes na parede celular. Já na região do EEM referente ao vermelho $(0,6$ e $0,7 \mu \mathrm{m})$ a radiação é absorvida pela 
clorofila nos tecidos fotossintetizantes das plantas, deste modo, quanto maior a biomassa vegetal de determinada espécie, menor será a porção refletida no Vermelho (MOTOMIYA et al. 2012).

$$
N D V I=\frac{N P P-V}{W V+V}
$$

Os índices de NDVI variam de -1 a 1 , sendo que os que se aproximam de um correspondem à áreas de densa vegetação, áreas de solo exposto apresentam valores que se aproximam de zero e áreas de completa ausência de vegetação (água) apresentam valores negativos (MENESES; ALMEIDA, 2012).

O dado de NDVI do sensor MODIS a bordo da plataforma Terra é disponibilizado através do produto MOD13A3, apresentando dados mensais e resolução espacial de 1000 metros. O sensor MODIS está acoplado tanto na plataforma Terra como na Aqua, e seus dados são distribuídos gratuitamente pela National Aeronautics and Space Administration (NASA), representando um grande avanço para o monitoramento em grande escala de eventos dinâmicos. O satélite Terra começou a ser operado no ano de 2000 e possui uma órbita decrescente, cruzando o equador às $10 \mathrm{~h} 30 \mathrm{~min}$ e $22 \mathrm{~h} 30 \mathrm{~min}$. O Satélite Aqua foi lançado em Maio de 2002 e passa pelo Equador às 13h30min e 01h30min em sua órbita ascendente (LATORRE, 2003).

MYD14 e MOD14

Os dados de queimada são oriundos do produto Thermal Anomalies and Fire (MYD14 e MOD14) estimados pelo sensor MODIS. Os produtos com prefixo MOD correspondem a dados estimados pela plataforma Terra, os dados com prefixo MYD são oriundos da plataforma Aqua e os produtos originados de informações de ambas as plataformas recebem a sigla MCD. Os produtos de anomalias termais e queimadas possuem 1 km de resolução espacial e juntos fornecem duas aquisições diárias (JUSTICE, 2011). 
Imagens Landsat 5 e 8

O satélite Landsat 5 iniciou suas operações em 1985, com dados estimados pelo sensor Thematic Mapper (TM). O sensor TM possui 7 bandas, cada uma representando uma faixa do espectro eletromagnético, com 30 metros de resolução espacial, resolução temporal de 16 dias e resolução radiométrica de 8 bits. As imagens obtidas pelo sensor Operational Land Imager (OLI) a partir do satélite Landsat 8 possui 30 metros de resolução espacial, 12 bits de resolução radiométrica e 9 bandas espectrais (USGS, 2013).

\section{Procedimentos Metodológicos}

Os dados do produto MOD13A3 são disponibilizados em tiles no formato Hierarchical Data Format (HDF). Os valores de x e y dos tiles equivalem a dez graus e são necessários 6 tiles (H12V09; H12V10; H12V11; H13V09; H13V10; H13V11) para cobrir toda a área do Cerrado, tornando necessário a realização de um mosaico a fim de que estes tiles sejam convertidos para um único arquivo em HDF para cada mês.

Os arquivos em HDF mensais (de 2000 a 2014) foram convertidos no programa Modis Reprojetion Tool (MRT) para o formato Tagged Image File Format (TIFF) e atribuída a projeção LAT/LON com Datum WGS84. Toda série temporal de NDVI foi contida em um único arquivo META e inserida no programa ENVI para a análise dos dados.

Para determinar e espacializar os focos de queimadas (produto MOD14 e MYD14), os dados para os mesmos tiles do produto de NDVI que também são disponibilizados no formato HDF foram transformados no American Standard Code for Information Interchange (ASCII) e contabilizados a partir de um programa em Fortran. Utilizou-se a linguagem Interface Description Language (IDL) para converter os dados para a projeção LAT/LONG e datum WGS84 e contabilizar a frequência de focos de queimadas durante o período de estudo (2000 a 2014). A contagem do número de focos é feita por um algarismo aplicado sobre uma grade $5 \mathrm{kmx} 5 \mathrm{~km}$, descrito na equação 2 .

$$
\text { Grade }_{(\text {lon,lat,MoDIS })}=\sum_{a--\alpha}^{\alpha} \sum_{b--\beta}^{\beta}\left(\chi(a, b)^{*} C(\text { Lon }+a, \text { lat }+b)\right.
$$

onde, $\chi(a, b)$ representa a convolução de uma máscara de dimensão $\mathrm{M}$ x N (Linhas x Colunas) e C a área queimada estimada pelo MODIS, enquanto que a Grade é definida por todos os pontos da máscara de dimensão $\mathrm{M}$ x $\mathrm{N}$ que sobrepõe a grade (lon $\epsilon[\alpha, \mathrm{M}-\alpha]$, lat $\epsilon[\beta, \mathrm{N}-\beta]$ ). 
No aplicativo ArcMap foram realizados os mapas finais dos focos de queimadas e sorteados 9 pontos distribuídos em todo cerrado. O critério de escolha destes pontos levou em consideração inicialmente a escolha de áreas com maior frequência de queimadas e uma distribuição equilibrada sobre o limite do bioma.

Estes pontos foram analisados a partir do arquivo META de NDVI utilizando a Transformada de Wavelet, que tem como característica representar os domínios espaço e frequência. Esta técnica matemática para a análise de sinais foi introduzida na década de 80 por Goupillaud et al., (1984) e Grossmann e Morlet, (1984), que tem como principal característica ressaltar atributos dinâmicos, ou seja, captar variações nos sinais das ondas (QUEIROZ et. al, 2011).

Desde modo, ao utilizar esta estatística é possível verificar as variações na frequência das ondas de NDVI para um determinado período de tempo, facilitando a observação de mudanças significativas nos valores dos IVs. A validação das informações inferidas a partir da Transformada Wavelet foi feita a partir de imagens oriundas dos Satélites Landsat 5 e 8 , para diversos anos.

\section{RESULTADOS E DISCUSSÕES}

As políticas de interiorização do governo para a região Centro-Oeste do Brasil entre as décadas de 1930 a 1960 tinham como principais objetivos ampliar o mercado interno, incentivar a migração e aumentar a produção agropecuária. A melhoria da infraestrutura e a instituição do crédito agrícola nesta região fizeram com que o Cerrado vivenciasse profundas mudanças na dinâmica de ocupação do seu território, tornando o "Celeiro do Mundo". Como resultado desta ocupação intensa no século passado a porção sul do bioma atualmente encontra-se antropizada com pouca presença de remanescentes florestais, enquanto que a frente agrícola avança para os estados localizados na porção norte (Tocantins, Maranhão, Piauí e Bahia), incentivados por programas de fomento das atividades privadas como o Fundo de Investimentos do Nordeste (FINOR) e o Fundo de Investimentos Setoriais (FISET) (MMA, 2011).

Coincidindo com o avanço da frente agrícola, os maiores registros de focos de queimadas para o período estudado (2000 a 2014) estão relacionados à porção norte do bioma, principalmente nos estados do Tocantins, Maranhão, Piauí e na porção oeste da Bahia. As queimadas no bioma estão condicionadas principalmente à estação de inverno no hemisfério sul, onde o clima seco e os baixos índices de precipitação na região relacionados ao acúmulo de biomassa podem ocasionar incêndios de grande proporção (Figuras 3 e 4). 
Os dois primeiros anos da série em questão (2000 e 2001) foram anos com poucos registros de incêndios, nos quais os focos foram estimados apenas pelo satélite TERRA e sua recorrência esteve relacionada principalmente aos estados localizados a norte do bioma. Para o ano de 2002 houve um aumento considerável no número de focos estimados pelos satélites AQUA e TERRA quando comparado com os anos de 2000 e 2001, porém a recorrência na distribuição espacial dos focos manteve-se na porção norte do bioma, nos estados do Tocantins, Maranhão, Piauí e na porção oeste da Bahia. Assim como em 2002, nos anos de 2003, 2004 e 2005 o número total de focos registrados ficaram próximos a 150000 e os maiores registros ocorreram na porção norte do Cerrado. O ano de 2006 foi um ano de poucas queimadas e antecedeu o ano de 2007, o ano com maior registro de focos de queimadas.

Figura 3: Distribuição espacial dos focos de queimada estimados pelos sensores MODIS para o Bioma Cerrado
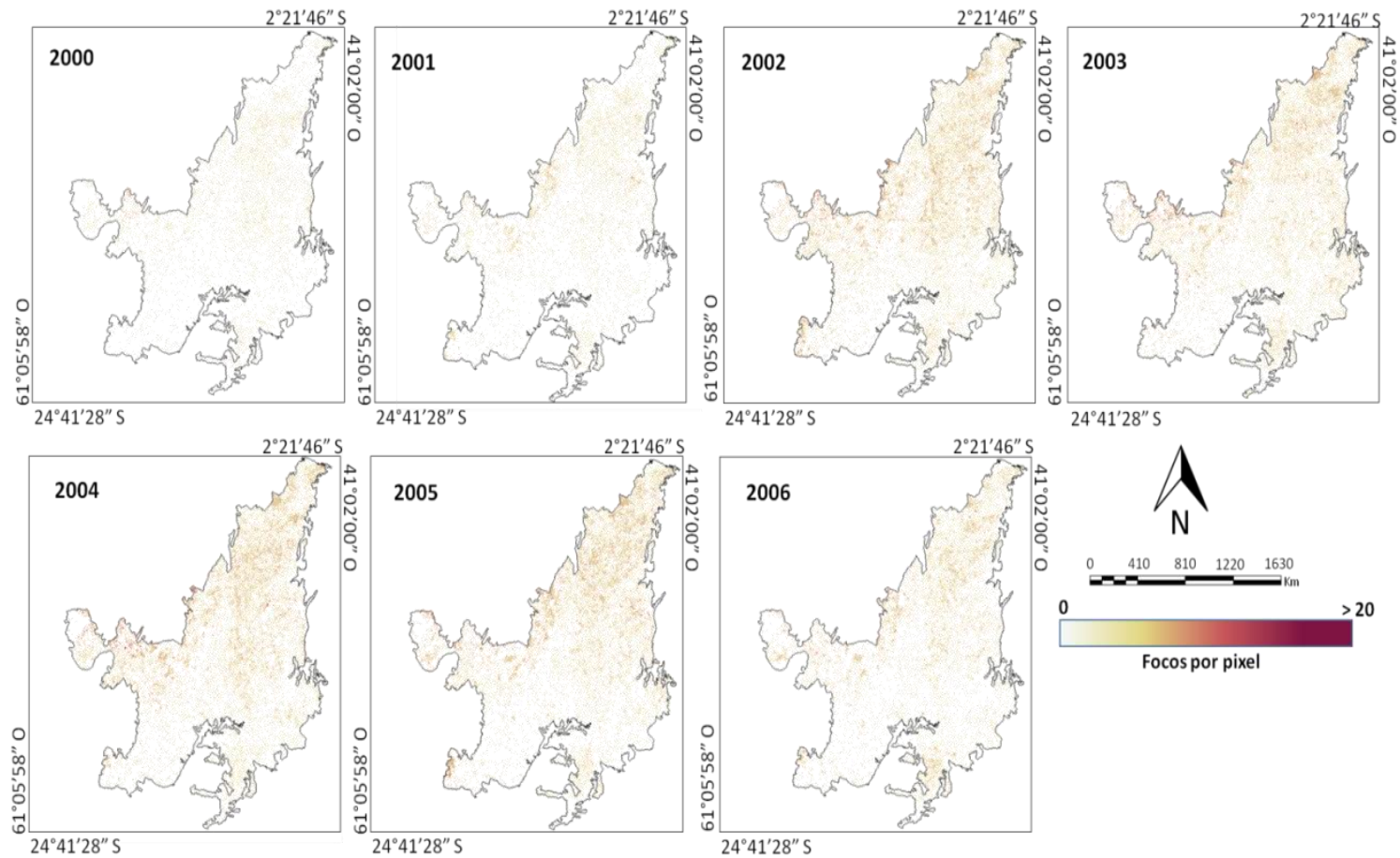

(2000 a 2006).

Para todos os anos, ainda que em menores quantidades do que a porção norte do Cerrado, houveram registros de focos de incêndios para a região do bioma no estado de São Paulo. Estes focos estão relacionados principalmente a queima dos canaviais para promover a limpeza das folhas secas e verdes e facilitar a colheita.

Nos anos de 2008 e 2009 houve poucos registros de focos de incêndios, sendo 2009 o ano com menor registro desde 2002, quando os focos passaram a ser detectados pelos satélites AQUA e TERRA. Em 2009 houveram maiores registros de precipitação, que aliada à 
menor frequência de incêndios ocasionou um acumulo de biomassa que se associou ao clima atipicamente seco de 2010, resultando no segundo maior registro de focos da série temporal estudada. Para estes anos citados, o maior número de focos estava relacionado à porção norte do bioma.

Em 2011 registrou-se um menor número de focos de incêndios, podendo indicar que após um ano de grandes queimadas as áreas frequentemente atingidas por incêndios necessitam de um período de tempo para que a vegetação se recomponha, para então ocorrer novos incêndios.
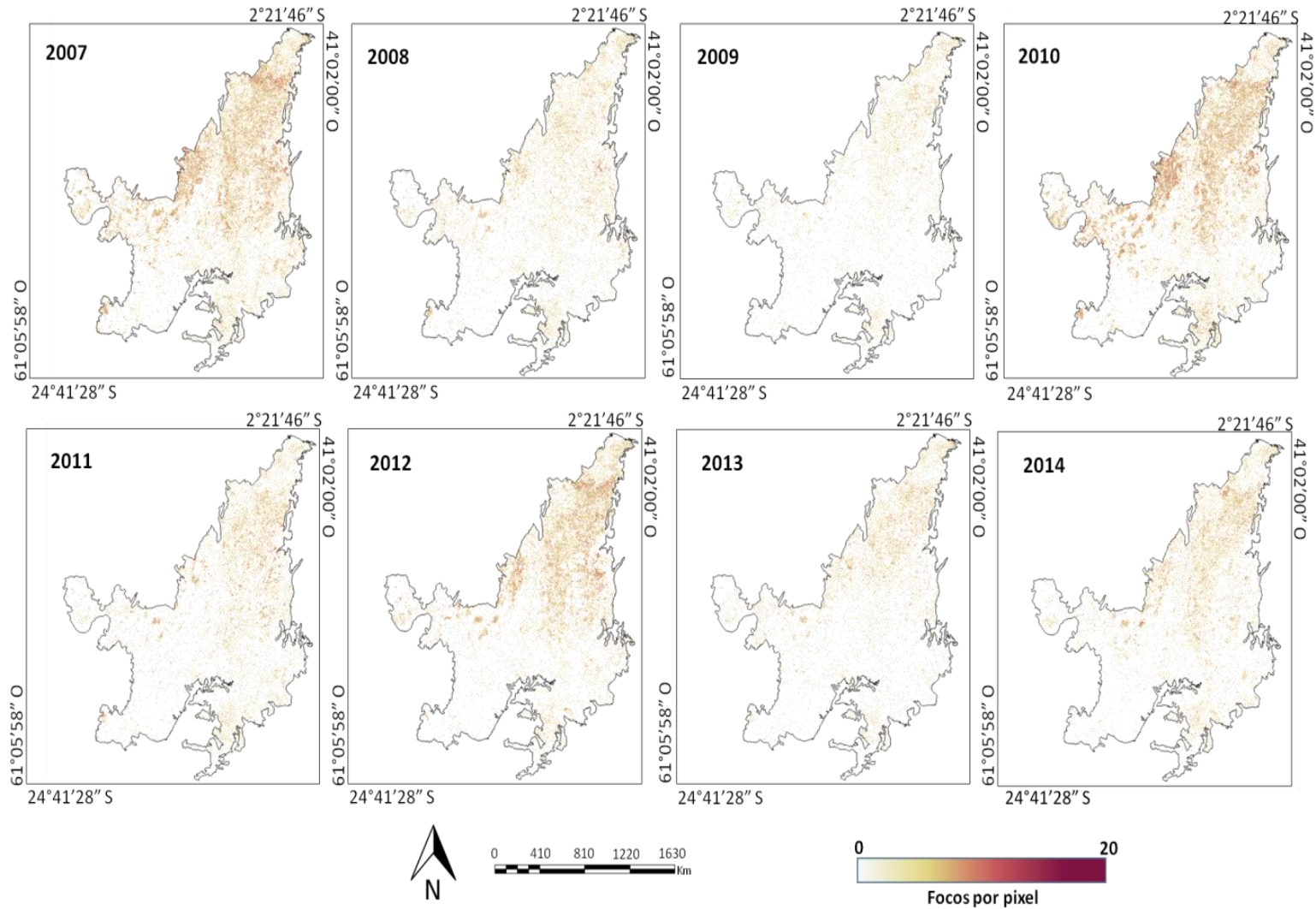

Figura 4: Distribuição espacial dos focos de queimada estimados pelos sensores MODIS para o Bioma Cerrado (2007 a 2014).

A espacialização dos focos de queimadas é importante para localizar as áreas do bioma que possuem maior recorrência de focos e associá-las com aspectos sócio-econômicos da dinâmica de ocupação do território brasileiro, enquanto que a quantificação dos focos (Figura 5) por ano permite uma melhor observação da dinâmica das queimadas para comparar os dados da série temporal.

Inicialmente, o número de focos para os anos de 2000 e 2001 são os menores registrados na série temporal devido à única aquisição diária realizada pelo satélite TERRA, com 39.794 e 52.298 focos, respectivamente. A partir de 2002, com duas aquisições diárias 
estimadas pelos satélites AQUA E TERRA o número de focos aumentou consideravelmente, totalizando 148478 focos. De 2003 para 2004 o número de focos registrados aumentou cerca de $14 \%$, passando de 134.671 para 154.457. O ano de 2006 foi um ano com poucos focos de queimada detectados quando comparado aos quatros anos que o antecederam (2002, 2003, 2004 e 2005), sendo registrados 88.664. Contrapondo o menor número de focos de 2006, 2007 foi o ano da série temporal com o maior número de focos de queimadas, totalizando 248.169 focos. Comparado a 2007, os dois anos seguintes (2008 e 2009) apresentaram menores registros, sendo contabilizados 100.119 e 57.729 focos, respectivamente. Já em 2010, o ano com o segundo maior número de registros, foram detectados 247.754 focos de queimadas. Em 2011 foram registrados 107.410 focos, seguidos por 2012 com 173.805. A partir de 2012 houve uma diminuição dos registros de focos de queimada até o fim da série temporal, contabilizando 82.838 e 121.547 focos para 2013 e 2014.

Observa-se que os anos que antecedem os maiores registros de queimadas, geralmente, há menores registros de focos. Isto ocorre porque toda a vegetação após a queima necessita de um período para que se possa realizar a sucessão ecológica, gerando o acúmulo de biomassa, que se associa a condições favoráveis para a ocorrência de novos incêndios. Na série, isto pode ser observado em 2006 e 2007; 2009 e 2010; e 2011 e 2012. Além disto, os maiores registros de focos de queimadas em 2007, 2010 e 2012 podem estar relacionados a queimadas em áreas que não haviam focos de incêndio nos outros anos, principalmente na porção oeste do bioma demonstrado na distribuição espacial dos focos.

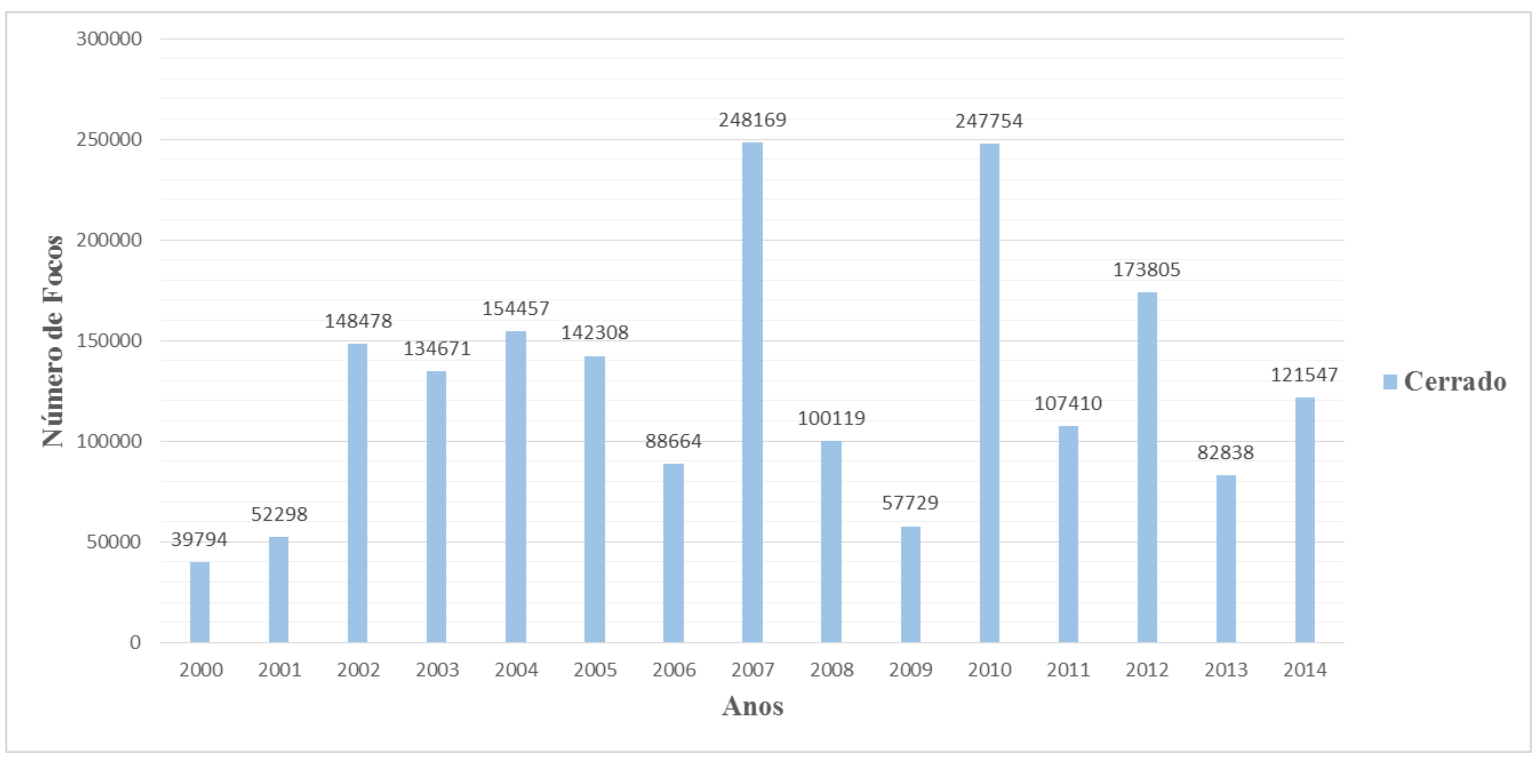

Figura 5: Número de focos detectados pelo Sensor MODIS para o Cerrado no período compreendido nos anos de 2000 a 2014. 
Com o propósito de analisar a interferência de áreas queimadas e compreender as mudanças no Uso e Cobertura da Terra (UCT) expressas no NDVI para o bioma Cerrado aplicou-se a transformada de Wavelet para facilitar a visualização das variações nos sinais das ondas do IV. Deste modo, foram selecionados 29 pontos amostrais aleatórios, dos quais foram selecionados 9 pontos para serem analisados com o propósito verificar alterações nos dados de NDVI mensais e comparar estas alterações com imagens dos satélites Landsat 5 e 8. Dentre os 9 pontos selecionados, foram escolhidos os quatro que apresentaram significativas mudanças nas ondas de NDVI para a análise.

\section{Ponto 1: Cerrado $\rightarrow$ Soja}

A variação temporal do NDVI no ponto 1 é dividida em três momentos distintos. O primeiro, onde não há alterações no sinal de NDVI até 2004, quando esta área sofre um decréscimo da biomassa que passa a ter uma variação fenológica a cada 64 meses, ou seja, a área foi desmatada e ficou abandonada até agosto de 2009 quando é convertida para fins agrícolas e destinada para a plantação de soja. Neste momento, a variação no sinal de NDVI passou a ser a cada 6 meses. 


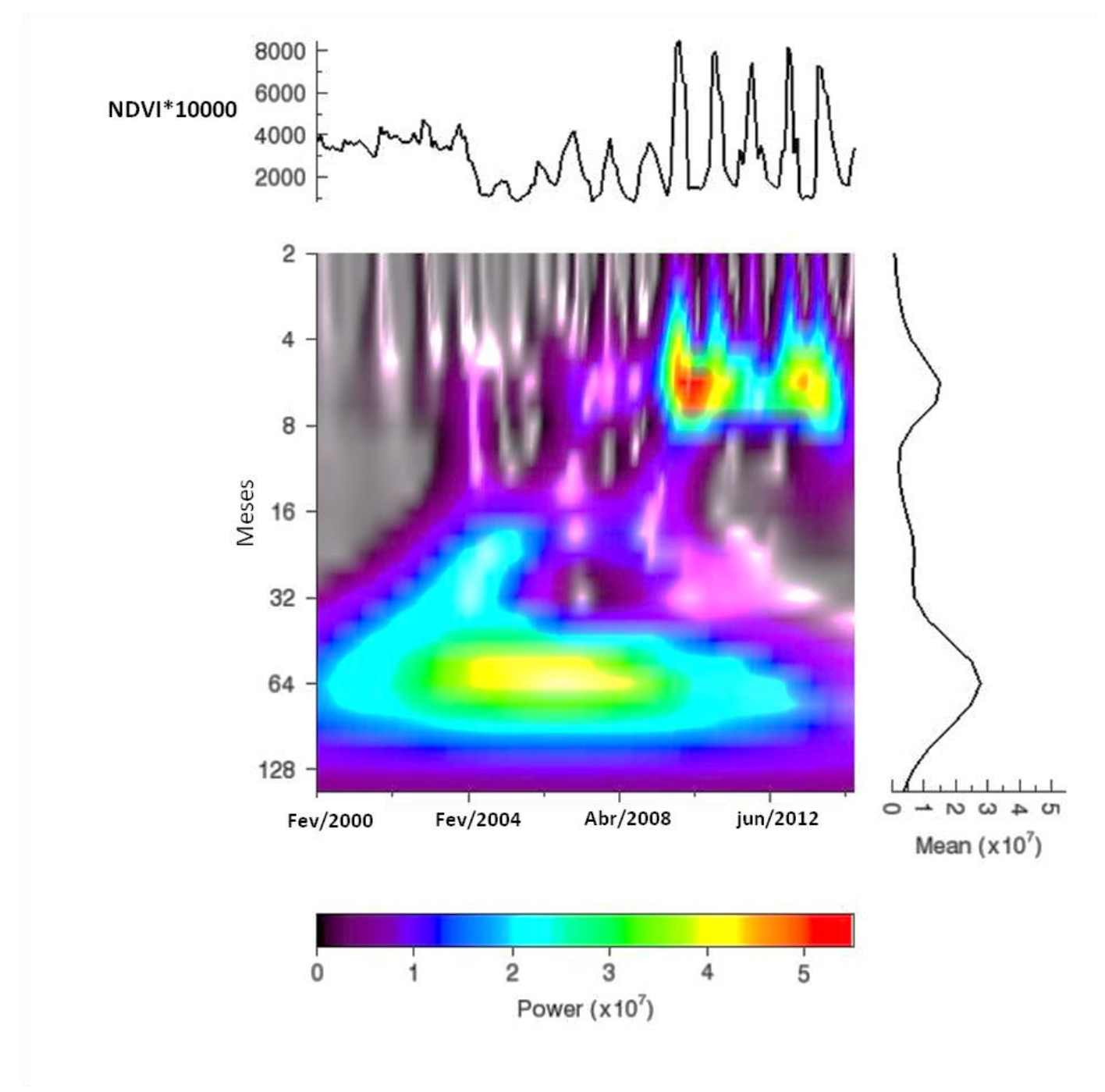

Figura 6: Tranformada Wavelet para o Ponto 1 (-46.01416296 O/ -12.91509099 S)

A Figura 7a representa o estágio inicial da área no início da série temporal em questão, apresentando uma vegetação rala circundada por áreas de expansão agrícola. A Figura 7b é referente ao período que a vegetação nativa foi desmatada e permaneceu abandonada, enquanto que a Figura 7c indica a conversão desta área para o plantio de soja. 


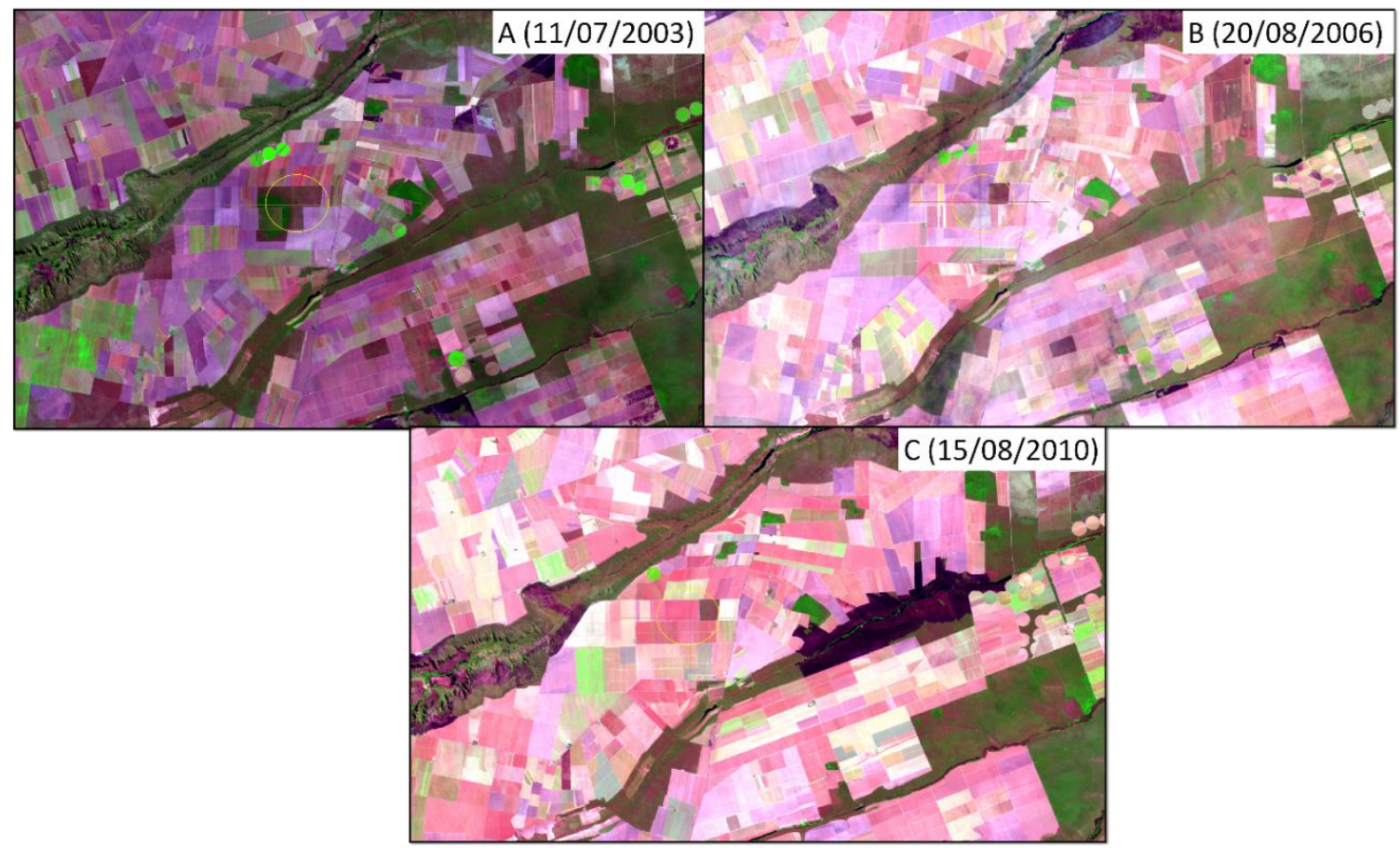

Figura 2: Ponto 1 destacado com um circulo amarelo. Imagens A, B e C foram estimadas pelo satélite Landsat 5.

\section{Ponto 2: Cerrado $\rightarrow$ Soja}

O sinal de NDVI diminui gradativamente desde o início da série até o ano de 2009, o que denota uma diminuição da biomassa, quando esta área foi convertida para fins agrícolas com uma cultura com fenologia a cada 6 meses, como demonstrado no sinal de NDVI. 


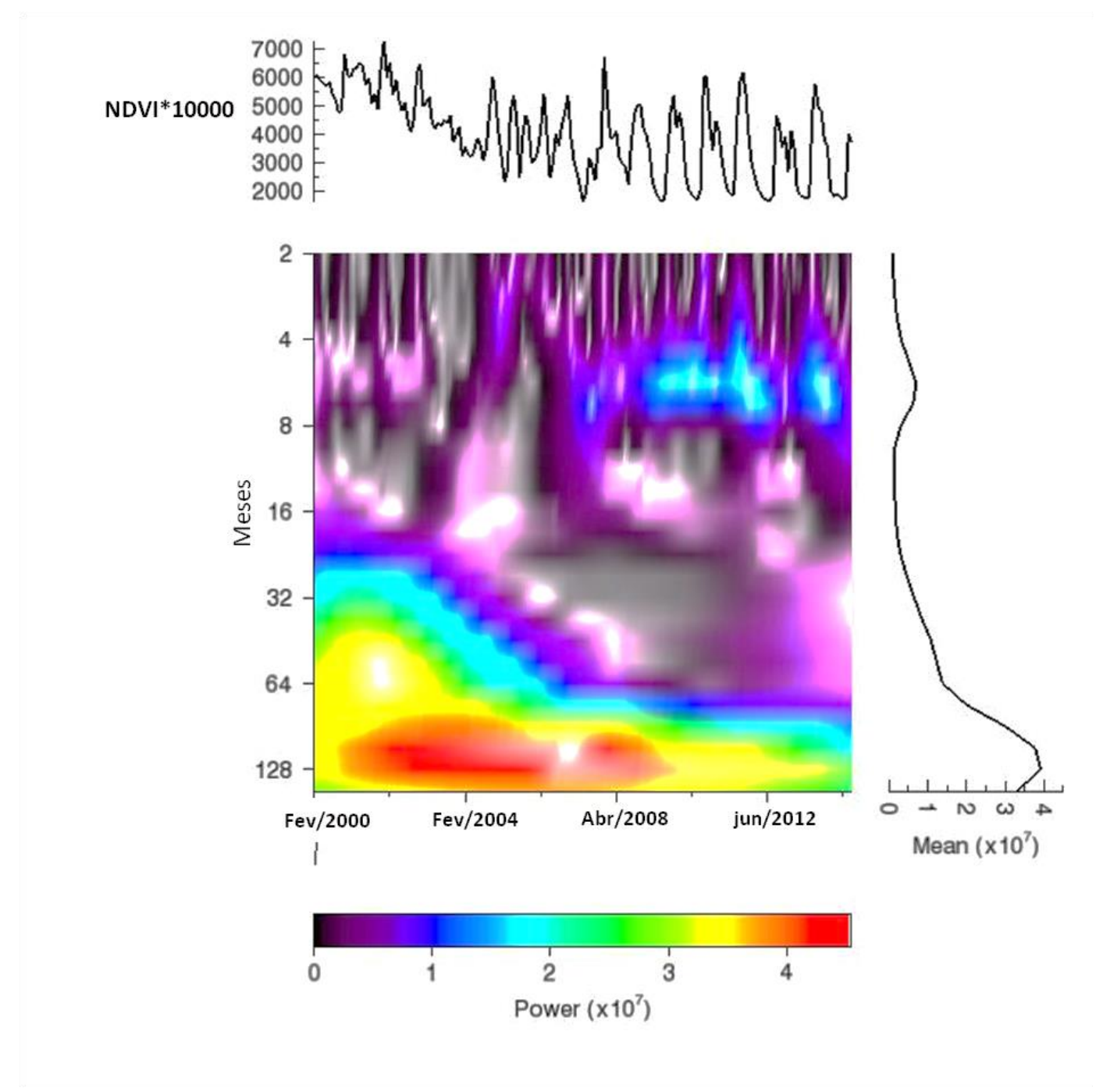

Figura 8: Tranformada Wavelet para o Ponto $2\left(-43.624397^{\circ} \mathrm{O} /-15.675832^{\circ} \mathrm{S}\right)$

Ao observar na Figura 9a, o ponto de estudo está próximo de pivôs, que possivelmente exerceram efeito de borda na vegetação e contribuíram para sua perda gradativa de biomassa vegetal. Na Figura 9b, em 2006, a área já apresenta uma grande redução de biomassa da vegetação que foi totalmente suprimida e deu lugar a plantações de soja (Figura 9c). 


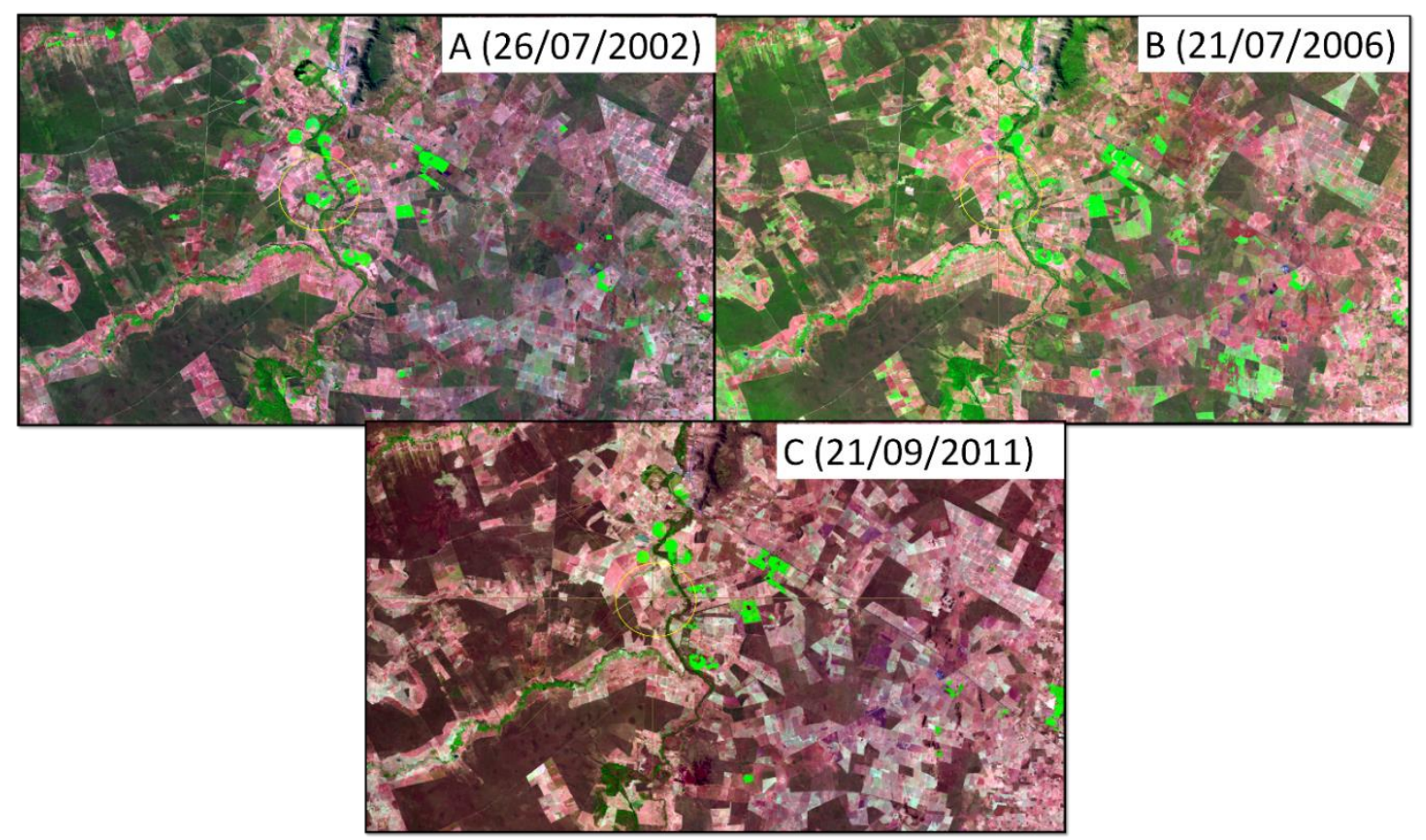

Figura 3: Ponto 2 destacado com um círculo amarelo. Imagens A, B e C foram estimadas pelo satélite Landsat 5.

\section{Ponto 3: Cerrado $\rightarrow$ Soja}

A variação temporal do NDVI no ponto 3 é dividido em três momentos distintos. O primeiro não há alterações no sinal de NDVI até 2004, quando esta área sofre um decréscimo da biomassa que passa a ter uma variação fenológica a cada 64 meses, ou seja, a área foi desmatada e ficou abandonada até agosto de 2009 quando é convertida para fins agrícolas e destinada para a plantação de soja, e a variação no sinal de NDVI passou a ser a cada 6 meses. 


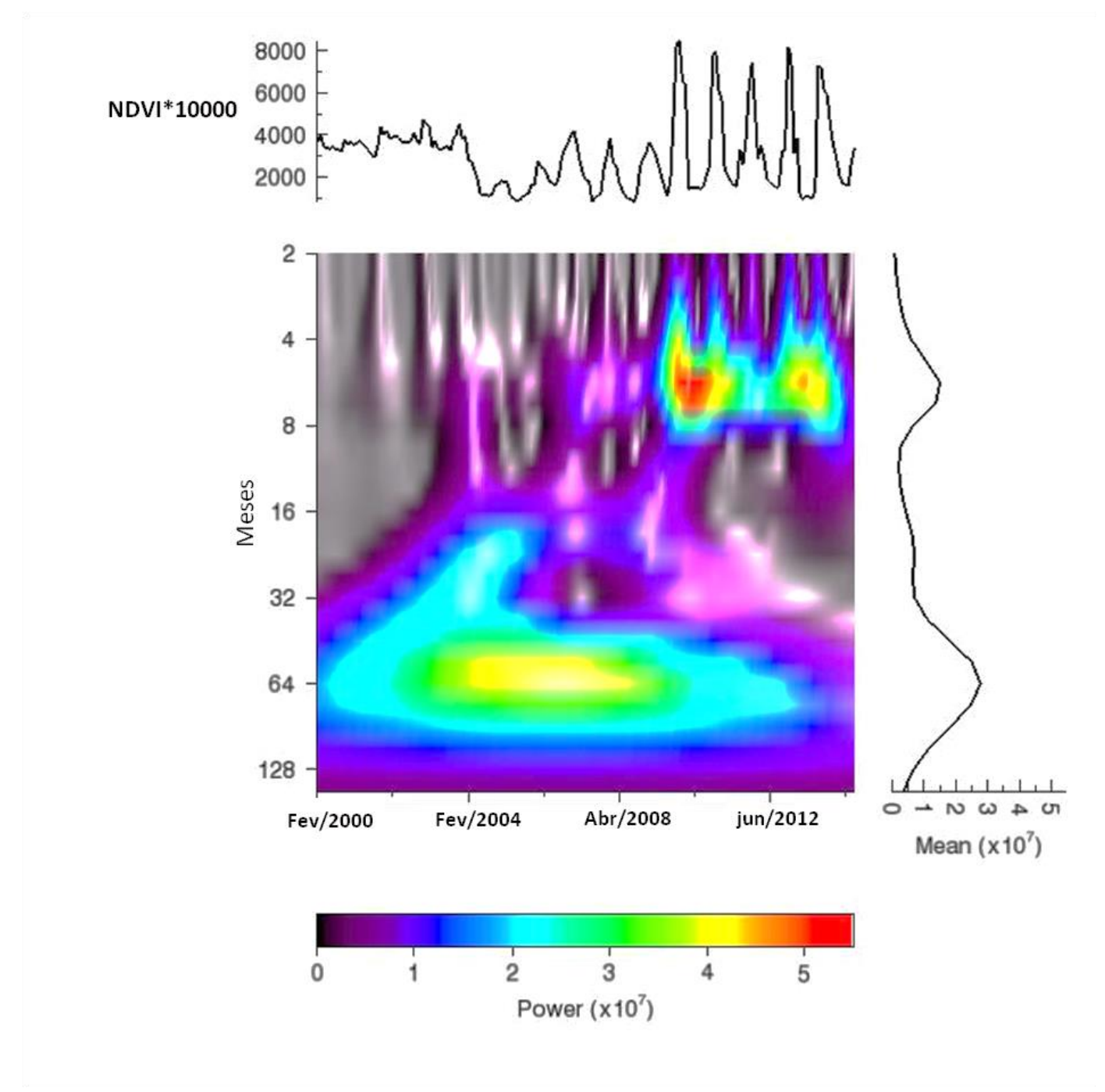

Figura 10: Tranformada Wavelet para o Ponto 3 (-46.01416296 O/ -12.91509099 S)

A Figura 11a representa o estágio inicial da área no início da série temporal em questão, apresentando uma vegetação rala circundada por áreas de expansão agrícola. A Figura $11 \mathrm{~b}$ é referente ao período que a vegetação nativa foi desmatada e permaneceu abandonada, enquanto que a Figura 11c indica a conversão desta área para o plantio de soja. 


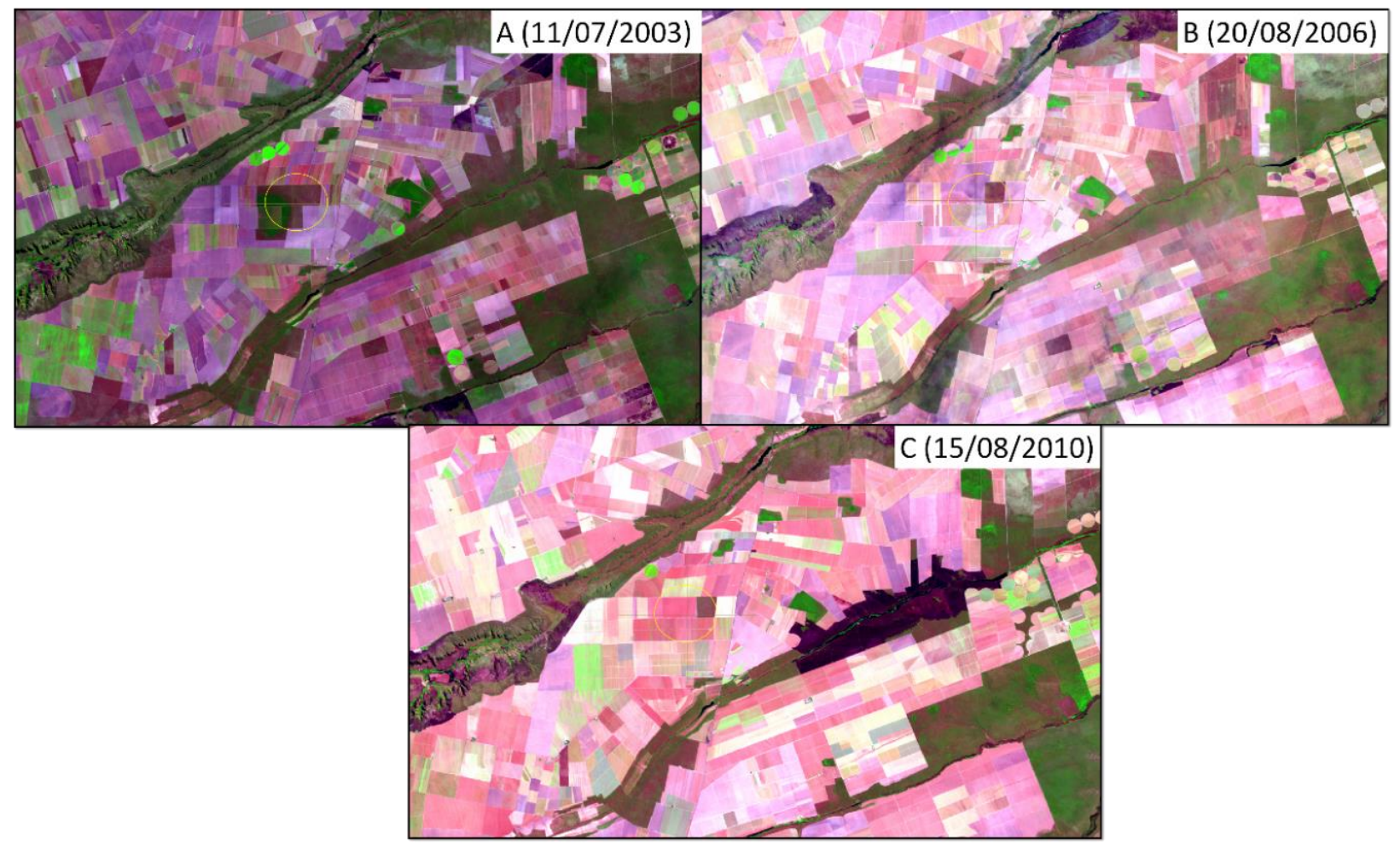

Figura 11: Ponto 3 destacado com um circulo amarelo. Imagens A, B e C foram estimadas pelo satélite Landsat 5 .

\section{Ponto 4: Cerrado $\rightarrow$ Pastagem}

Os dados de NDVI referentes ao ponto 4 indicam que a vegetação desta área passou por três fases. A primeira, que se estente do início da série temporal até aproximadamente julho de 2008, quando a área ainda possuia sua vegtação nativa e uma variação no sinal de NDVI a cada 6 meses. A segunda fase ocorre quando esta área é desmatada restando solo exposto apresentado no grafico indicado pela variação da fenologia de 64 meses, até setembro de 2009. A terceira fase corresponde a introdução de gramíneas para pastagem, que passa a ter uma variação no sinal de NDVI a cada 6 meses, coincidindo com a variação sazonal da precipitação para a região. Ao final da série demonstrada no gráfico da tranformada, o sinal do NDVI não apresenta variação. 

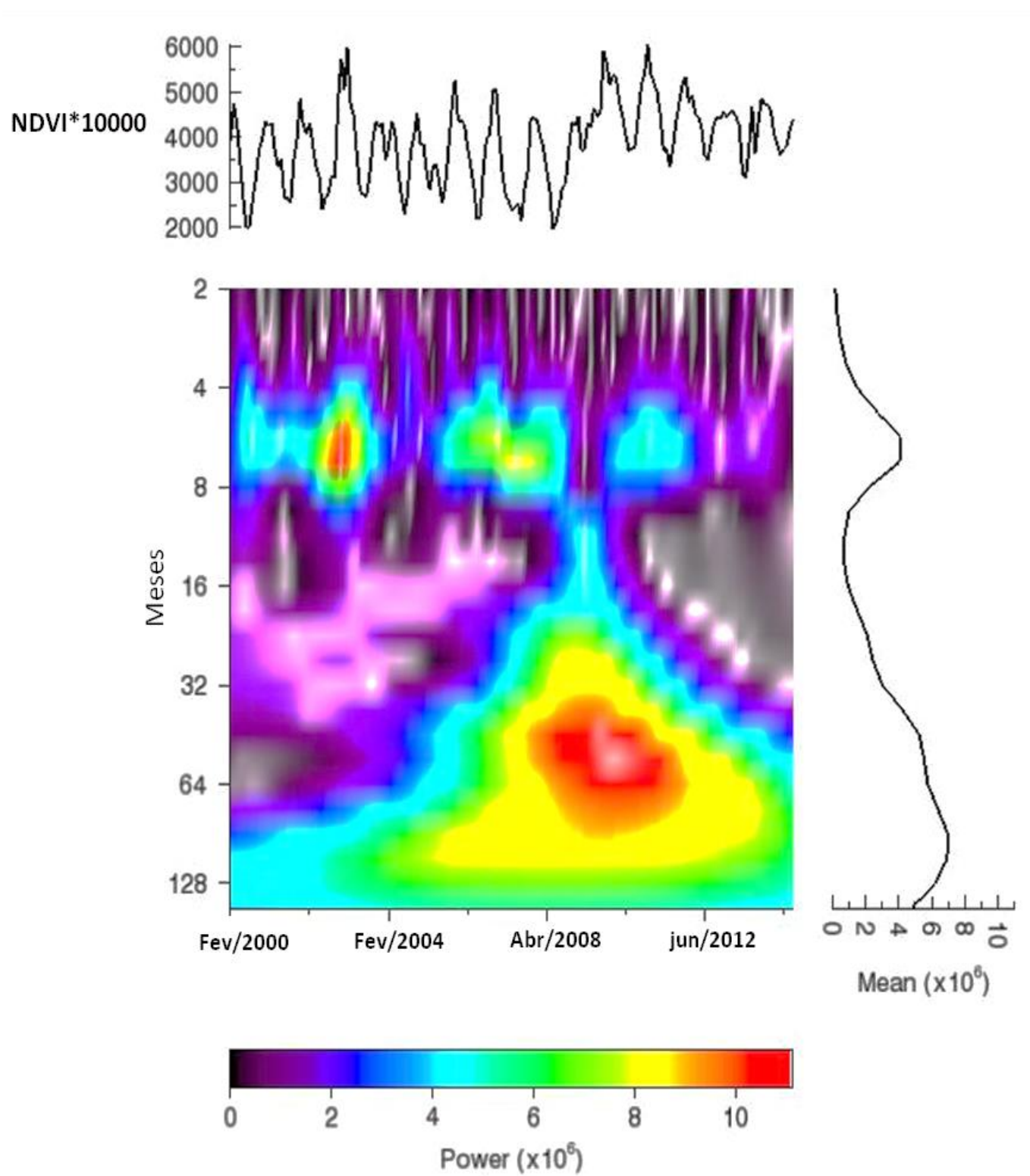

Figura12: Tranformada Wavelet para o Ponto 5 (-55.45244589 O/ -20.62791086 S)

Ao comparar as anomalias observadas no gráfico com imagens de satélite observa-se que em um primeiro momento (Figura 12a) esta área possuía uma vegetação de Cerrado ralo, que foi suprimido deixando a área com o solo exposto (Figura 12b). A Figura 12c demonstra a conversão desta área para pastagem. 


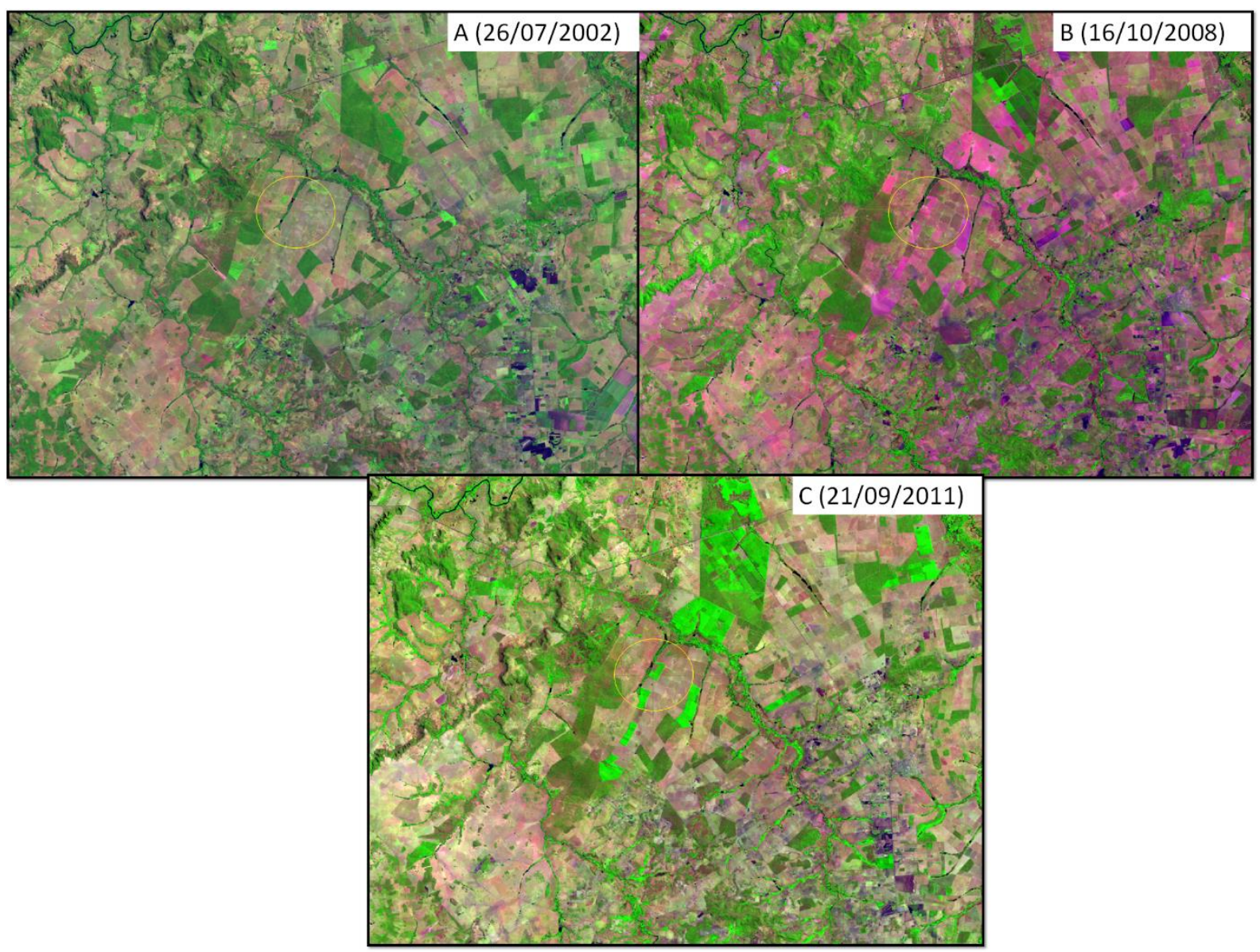

Figura 4: Ponto 4 destacado com um circulo amarelo. Imagens A, B e C foram estimadas pelo satélite Landsat 5.

\section{CONSIDERAÇÕES FINAIS}

O maior número de focos de queimadas estão relacionados à porção norte do bioma, que possui uma tendência à antropização para os próximos anos, onde novas frentes agrícolas avançam sobre esta região nos estados do Maranhão, Piauí, Bahia e Tocantins. As grandes quantidades de focos associadas ao bioma contribuem para a emissão de gases traços e aerossóis, responsáveis por mudanças climáticas em âmbito local, regional e até mesmo global.

A expansão da matriz agrícola na porção Norte do bioma será consolidada a partir do projeto MOTOPIBA, criado em 2014, resultado de uma parceria entre a Empresa Brasileira de Pesquisa Agropecuária (EMBRAPA) e o Instituto Nacional de Colonização e Reforma Agrária (INCRA) e prevê a expansão da fronteira agrícola baseada em tecnologias modernas de alta produtividade. A sigla é resultado do acrônimo das iniciais dos estados do Maranhão, Tocantins, Piauí e Bahia, evidenciando que a dinâmica do uso e cobertura da Terra nestas 
regiões continuará sendo mudada substancialmente nos próximos anos, ressaltando a necessidade de estudos futuros que completem a série história deste trabalho.

Além disto, a Moratória da Soja que trata de um acordo entre o Ministério do Meio Ambiente e setor produtivo para que a soja oriunda de áreas desflorestadas no bioma Amazônia não seja comprada, associada ao novo Código Florestal (Lei No 12.651, de 25 de Maio de 2012) que prevê que 80\% do imóvel rural situado em áreas de florestas na Amazônia Legal seja considerado reserva legal, direciona o avanço da fronteira agrícola para áreas do bioma Cerrado, que são obrigados a preservar 35\% da sua área a título de reserva legal dentro da Amazônia Legal e 20\% nas demais áreas. Neste cenário, a conjunção destes fatores indica que a exploração agrícola seguirá para os próximos anos, trazendo riscos aos ecossistemas do Bioma.

Devido a extensão do bioma (aproximadamente 2 milhões de $\mathrm{km}^{2}$ ) o uso de SIG constitui uma ferramenta de baixo custo para monitorar em séries históricas as dinâmicas de uso e cobertura da terra, obter parâmetros biofísicos da vegetação (IVs) e quantificar e especializar os focos de queimadas. A utilização da Transformada de Wavelet para avaliar alterações nos sinais de NDVI se mostrou uma boa ferramenta para detectar mudanças do uso e cobertura através da observação das anomalias nos sinais, além disto, a utilização de imagens de satélite de média resolução valida a observação do NDVI e ilustram as variações para determinadas áreas. Desta maneira, os dados deste trabalho podem fomentar estudos que visam o planejamento do espaço, auxiliando na construção de um cenário de degradação durante os catorze anos da série em questão (2000 - 2014) e subsidiar políticas públicas de conservação do Cerrado.

\section{REFERÊNCIAS BIBLIOGRÁFICAS}

AB'SABER, A. N. A Organização Natural das Paisagens inter e subtropicais brasileiras. In: FERRI, M. G. Simpósio sobre o Cerrado. São Paulo: Edgard Blucher Ltda.: EDUSP, 1971.

AGUIAR, T. J. A.; MONTEIRO, M. S. L. Modelo agrícola e desenvolvimento sustentável: a ocupação do cerrado piauiense. Ambiente e Sociedade, Campinas, v. 8, n. 2, p.1-18, nov. 2005. Disponível em: <http://www.scielo.br/pdf/asoc/v8n2/28610.pdf>. Acesso em: 02 set. 2015. 
ANDERSON, L. O. et al. Detecção de cicatrizes de áreas queimadas baseada no modelo linear de mistura espectral e imagens índice de vegetação utilizando dados multitemporais do sensor MODIS/TERRA no estado do Mato Grosso, Amazônia brasileira. ACTA Amazonica Manaus, V. 35, n. 4. P. 445 - 456, Oct./Dec. 2005.

ANDREAE, M. O. Biomass burning: its history, use, and distribution and its impact on environmental quality and global climate. In: levine, J. S. (Ed.). Global biomass burning: atmospheric, climatic, and biospheric implications, The MIT Press, Cambridge, MA, p. 2-21, 1991

BELCHER, C. M . Fire Phenomena and the Earth System: An Interdisciplinary Guide to Fire Science An Interdisciplinary Guide to Fire Science. College of Life and Environmental Sciences, University of Exeter, 2013.

BORLAUG, N. E. 2002. Feeding a world of 10 billion people: the miracle ahead. In: BAILEY, R. (ed.). Global warming and other eco-myths. p. 29-60. Competitive Enterprise Institute, Roseville, EUA.

COCHRANE, M. A. Tropical Fire Ecology: Climate change, Land use and Ecosystem Dynamics. Praxis Plublishing Ltd, Chichester, UK, 2009.

GOUPILLAUD, P., GROSSMANN, A., MORLET, J. Cycle-octave and related transforms GROSSMAN A., MORLET J. Decomposition of Hardy Funtion into Square Integrable Wavelet of Constante Shape. SIAM J. Math., USA, v.15, pp. 723-736, 1984.

GROSSMANN, A., MORLET, J.. Decomposition of Hardy functions into square integrable wavelets of constant shape. SIAM Journal on Mathematical Analysis, v 15, n 4, 723 - 736p, 1984.

JUSTICE, C. O et al. MODIS-Derived Global Fire Products. In: RAMACHANDRAM, B.; JUSTICE, C. O.; ABRAMS, M. J. (Eds.). Land Remote Sensing and Global Environmental Change: NASA's Earth Observing System and the Science of ASTER and MODIS (Remote Sensing and Digital Image Processing). New York: Springer, 2011. 873p.

LATORRE, M. L. et al. Sensor Modis: Características Gerais e Aplicações. Espaço \& Geografia, Brasília, v.6, n.1, p. 91-121, 2003. 
LIMA, J. E. F. W.; SILVA, E. M.. Recursos hídricos do Bioma Cerrado: Importancia e situação. In: SANO, S. M.; ALMEIDA, S. P.; RIBEIRO, J. F. Cerrado: Ecologia e Flora. Embrapa Cerrados. Brasília, DF: Embrapa Informação Tecnológica, 2008

MENESES, P. R.; ALMEIDA, T. (Org.). Introdução ao Processamento de Imagens de

Sensoriamento Remoto. Brasília: Unb, 2012. p. 1-266. Disponível em: <http://www.cnpq.br/documents/10157/56b578c4-0fd5-4b9f-b82a-e9693e4f69d8>. Acesso em: 02 set. 2015.

MINISTÉRIO DO MEIO AMBIENTE. Plano de ação para prevenção e controle do desmatamento e das queimadas: cerrado. Brasília: MMA, 2011. 200 p.

MIRANDA, H. S. et al. The Fire Factor. In: OLIVEIRA, P. S.; MARQUIS, R. J. (eds.). The Cerrado of Brazil: Ecology and natural history of a neotropical savanna. New York: Columbia University Press, 2002. 69-88 p.

MOTOMIYA, A. V. de A. et. al. Mapeamento do Índice de Vegetação da Diferença Normalizada em Lavoura de Algodão. In: Pesq. Agropec. Trop., Goiânia, v. 42, n. 1, p. $112-$ 118, jan./mar 2012.

NEPSTAND, D. C.; MOREIRA A. G.; ALENCAR, A. A.. A floresta em chamas: origens, impactos e prevenção do fogo na Amazônia. Programa Piloto para a Proteção de florestas tropicais do Brasil, Brasília, Brasil, 1999. 202 p.

NETO, G. G.; MORAIS, R. G.. Recursos Medicinais de Espécies do Cerrado de Mato Grosso: Um estudo Bibliográfico. Acta Botânica Brasília, São Paulo, V. 17, n. 4, p 561-584, Oct./Dec. 2003.

QUEIROZ, R. el al. Improving daily Rainfall Estimation from NDVI using a Wavelet Transform. Environmental Modelling \& Software, v. 26, n. 2, 201 - 209 p, Fev 2011. 
RIBEIRO, J. F.; WALTER, B. M. T.. As principais fitofisionomias do Bioma Cerrado. In: SANO, S. M.; ALMEIDA, S. P.; RIBEIRO, J. F. Cerrado: Ecologia e Flora. Embrapa Cerrados. Brasília, DF: Embrapa Informação Tecnológica, 2008.

ROUSE, J.W. et al. Monitoring vegetation systems in the great plains with ERTS. In: Earth Resources Tecnology Satellite- 1 Symposium,3, 1973. Proceedings. Washington, 1973, v.1, Sec. A, p. 309-317.

USGS - United States Geological Survey. Landsat: A Global Land-Imaging Mission. 2013. Disponível em: http://pubs.usgs.gov/fs/2012/3072/fs2012-3072.pdf. Acesso: 03 Julho 2015. 